Int. J. Dev. Biol. 52: 219-227 (2008)

doi: $10.1387 / \mathrm{ijdb} .072335 \mathrm{jm}$

\title{
From Planarians to Mammals - the many faces of regeneration
}

\author{
JERZY MORACZEWSKI*, KAROLINA ARCHACKA, EDYTA BRZOSKA, MARIA-ANNA CIEMERYCH, IWONA \\ GRABOWSKA, KATARZYNA JANCZYK-ILACH, WLADYSLAWA STREMINSKA and MALGORZATA ZIMOWSKA
}

Department of Cytology, Institute of Zoology, Faculty of Biology, University of Warsaw, Warsaw, Poland

\begin{abstract}
This report presents the history of the involvement of the Department of Cytology in studies of different aspects of regeneration. It can be divided into two major phases; the first focused on the regeneration of Turbellarians and the second on the regeneration of rat skeletal muscles including the differentiation of satellite cells in vitro. Regeneration of Turbellarians was investigated both at the cellular and molecular levels including the role of the protein kinase $\mathrm{C}$ (PKC) in this process. Studies on skeletal muscle regeneration initially focused on factors involved in regulation of signal transduction pathways. Next, we explored the influence of growth factors on the modulation of the regeneration process. Another important aspect of our studies was investigating of the distribution and function of different proteins involved in adhesion and fusion of myoblasts. Finally, we are also conducting research on the role of stem cells from other tissues in the regeneration of skeletal muscle.
\end{abstract}

KEY WORDS: regeneration, planaria, skeletal muscle

In this report we present the history of the involvement of the Department of Cytology team in the studies on regeneration dated from 1974. This research may be divided into two major phases. First, we concentrated our efforts on the regeneration of Turbellarians. Then, in 1987, we switched our research model to the regeneration of the rat skeletal muscle and the differentiation of satellite cells in vitro. In this article we demonstrate the main topics of the studies conducted solely by the members of our group or in collaboration with other laboratories.

\section{Planarian regeneration}

Planarians serve as a good model for the study of cell differentiation. Due the presence of totipotent stem cells they are characterized by an unique ability to regenerate. These stem cells (neoblasts) are responsible for the regeneration and growth. Neoblasts are true totipotent stem cells, like embryonic stem cells in vertebrates. They can be involved in the differentiation of all planarian tissues. Turbellarian of the order Catenulida were cultured in our laboratory for 6 years and served those days as a subject of various studies (Fig. 1). Our first publication in that we focused at Catenula concerned its asexual reproduction and regeneration (Moraczewski, 1977). The examination of the ultrastructure of the myodermal body wall by (Moraczewski and Czubaj, 1974) and (Soltynska et al., 1976), as well as of the nervous system by (Moraczewski et al., 1977a, Moraczewski et al., 1977b), made it possible to trace precisely the course of regeneration and paratomy i.e. transverse fission during which differentiation of new organs occurred prior to separation from the mother animal (Fig. 1 A,B). These studies showed that fissioning in Catenulawas a typical paratomy as defined by (Wagner, 1890). The Catenulaspecies analyzed by us always divided into only two zooids, and fission always occurred behind the intestine. The opisthe i.e. he posterior daughter organism after transverse division, always re-formed the brain, gullet, and intestine. Both experimental and ultrastructural studies indicated that paratomy takes place in exactly the same way as regeneration. Cell differentiation follows an identical course and the order of appearance of the organs is the same. In Tricladida regeneration occurs by means of epimorphosis (i.e. regeneration in which cell proliferation precedes differentiation), whereas in Catenula new structures are differentiated within the old organism, in the old morphogenetic field. We assumed that the presence of the endoderm was essential for regeneration in Catenula. Parts of the body deprived of endoderm did not regenerate at all. The streaks of undifferentiated cells behind the intestine, appearing after fission and composed of neoblasts, were used during growth and differentiation (Fig. 1C). In Catenula, regeneration and paratomy follow

Abbreviations used in this paper: ECM, extracellular medium; EDL, extensor digitorum longus (muscle); HGF, hepatocyte growth factor; IGF, insulinlike growth factor; PKA, protein kinase A.

\footnotetext{
*Address correspondence to: Jerzy Moraczewski. Department of Cytology, University of Warsaw, Miecznikowa 1 St., Warsaw 02-096, Poland. Fax: +482-2554-1203. e-mail: jmlabo@biol.uw.edu.pl Web: www.biol.uw.edu.pl/cytologia
}

Published online: 14 February 2008 
similar courses, hence, both these processes must be controlled in the same or a very similar manner. Our research allowed us to present a hypothetical model of the mechanisms controlling these processes, in accordance with Wolpert's postulates (Wolpert, 1969, Wolpert, 1971). In order to differentiate a new field (or individual organism), fission of the old morphogenetic field must take place or this field must increase to such an extend that part of it would lie beyond the coordinates defining the boundaries of this field.

The regeneration has long been one of the basic problems of Turbellarian biology. Again, Planarians seemed to be extremely suitable for carrying out investigations in this field. Moreover, long lasting studies on regeneration resulted in numerous observations concerning morphological processes occurring during regeneration. However, little was known about this process at the cellular level and almost no data concerning the molecular aspects of this phenomenon were available. The most significant events seemed to occur 2 or $3 \mathrm{~h}$ after sectioning or wounding of an organism. Afterwards, the usual wave of proliferation and differentiation took place. The problems of cell activation in this period was investigated in our laboratory using biochemical methods with collaboration with the laboratory of Prof Le Moigne from Paris XII University and by means of ultrastructural cytochemistry (Moraczewski, 1981). We showed that in Turbellaria during regeneration, a great number of undifferentiated cells (neoblasts) became activated and thus were able to proliferate. Amputation of either part of a turbellarian, or an amphibian's limb, or the column of a Hydra disrupts the whole system of coordinates deciding of the cell fate. If, among the remaining cells, the quiescent, undifferentiated cells (stem cells) would be present, they could be stimulated to differentiate and proliferate. This stimulus is transmitted probably by the aminenergic neurohormones serotonin and catecholamines (Franquinet, 1979, Franquinet and Catania, 1979, Franquinet and Martelly, 1981, Lender and Klein, 1961, Lenicque, 1973). Adenylate cyclase (AC) is an enzyme that plays a key role in the serotonin signalling pathway. AC activity changes in relation to changes in serotonin levels (Franquinet et al., 1978, Franquinet et al., 1976). Using ultracytochemical methods we observed that the highest AC activity occurred in the second and third hour of regeneration (Moraczewski and Duma, 1978, Moraczewski and Duma, 1981). Consistent with the change in AC activity, the CAMP levels increased six-fold in the second hour (Franquinet and Le Moigne, 1979, Le Moigne etal., 1976). We observed a correlation between the CAMP level in turbellarian tissues and the activity of cAMPdependent protein kinases (PKA) (Moraczewski and Franquinet, 1980). A rapid increase of CAMP in a regenerating planarian caused a distinct increase of PKA activity. At the same time we noted considerable increases in the activity of cyclic 3',5'-nucleotide phoshodiesterase (Duma and Moraczewski, 1980). These biochemical and ultracytochemical studies focused on phenomena occurring in the first three hours of regeneration. Then, between third and sixth hour the process of neoblasts differentiation begins.

Between 1983 and 1987 our research was focused on the role of protein kinases and protein phosphorylation during planarian regeneration. Firstly, PKA and $\mathrm{Ca}^{2+}$ dependent protein kinase (PKC) were characterized in the Planarian (Moraczewski et al., 1983). The optimal conditions for their functioning were deter-

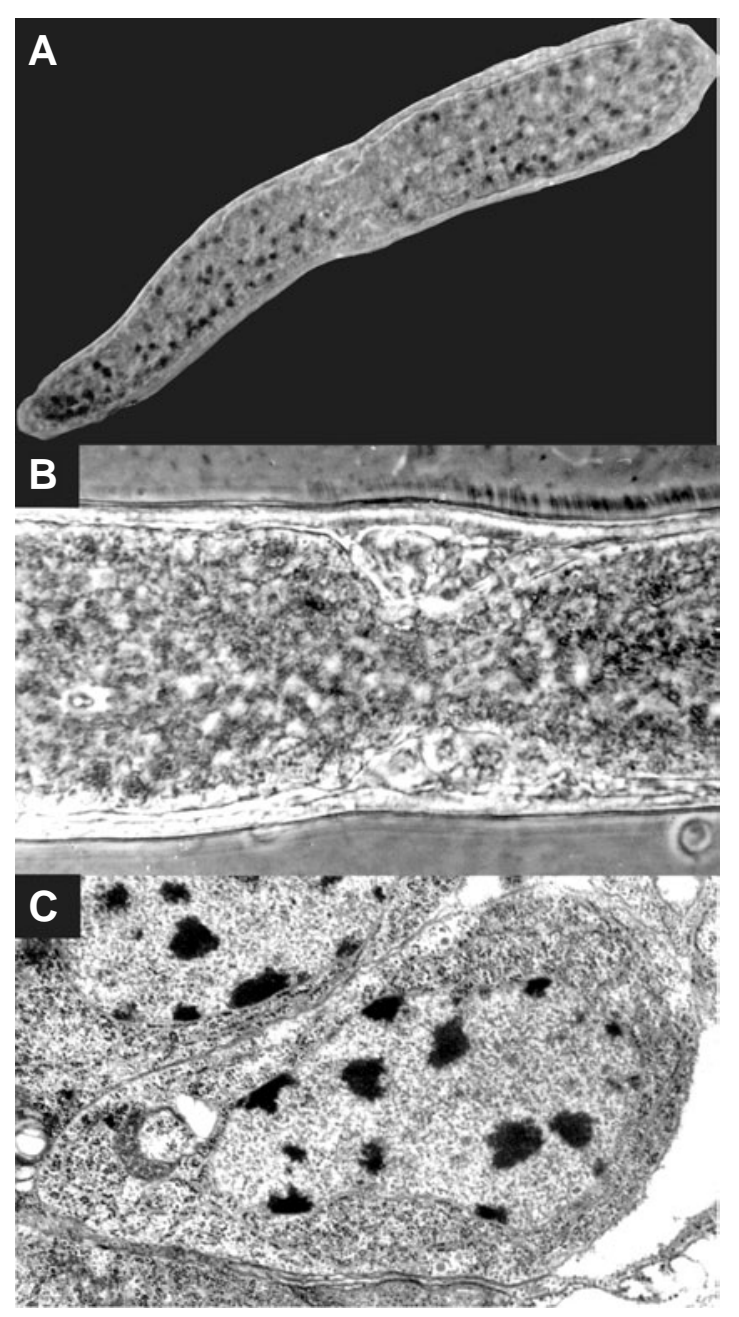

Fig. 1. Catenula. (A) Division of a living Catenula as seen under phase contrast. (B) Region of paratomy. (C) Ultrastructure of Catenula's stem cell.

mined. Both enzyme activities varied during regeneration. Protein kinase activity was correlated with adenylate cyclase activity, neuromediator and $\mathrm{Ca}^{2+}$ levels. These results confirmed that regeneration machinery started immediately after the incision. $A$ drop in $\mathrm{Ca}^{2+}$ level during the first three hours of regeneration was accompanied by variation in neuromediators, adenylate cyclase and kinase activities. During this important period of the regenerative process, the mechanism of proliferation and differentiation may have been activated.

We were the first group to report results of biochemical studies on variation in endogenous protein phosphorylation during the initial 24 hours of planarian regeneration, (Moraczewski et al., 1986). We explained this phenomenon as the result of combined activities of PKC, $\mathrm{Ca}^{2+}$ and PKA. Interestingly, the pattern of nuclear protein phosphorylation, especially that of histones, was related with the events occurring in a $24 \mathrm{~h}$ cell cycle, during which we observed massive induction of proliferation.

In 1987, with the collaboration with Dr. M. Castagna, we were the first to publish the study on the role of protein kinase $\mathrm{C}$ activity during Planarian regeneration (Moraczewski et al., 1987). In an intact adult Planarian, about $84 \%$ of the PKC total activity was 
found in the cytosolic fraction and the remainder in the membranes. This paper was our last focusing on planarian regeneration.

The regeneration of Planarians concerned all organism, so it differs from the regeneration process of tissues or organs in higher organisms. However, the basic mechanism of this process follow in similar way. The regeneration depends on the presence of stem cells. Currently, the neoblasts of Turbellaria are acknowledged as totipotent cells and still are in the centre of interests of many researchers.

From 1987, in close cooperation with group of Prof. Le Moigne (University of Paris XII), we decided to study regeneration using a different model. Skeletal muscle regeneration and myoblasts differentiation became our new fascination.

\section{Skeletal muscle regeneration}

The regeneration of muscles is physiological response of the tissue to traumatic or pathological injuries. Its progress depends on the extent of the injury and the type of damaged muscle. Te presence of satellite cells, conserved in the uninjured fragments of the basal membrane of the myofibre, along with the ability of being reinnervated and revascularized, is a vital condition for successful regeneration (Bassaglia and Gautron, 1995). Following muscle injury, myofibers become completely disintegrated via myolysis. During this process, the satellite cells are released from underneath the basal membrane. Starting from this moment these cells vigorously divide, and then differentiate into muscle fibers, which in turn are able to reconstruct correctly both the architecture and the function of the muscle. Any interruptions in proliferation, myoblast fusion or disruptions in the extracellular matrix lead to the development of fibrosis, which results in the disruption of the muscle function. The proliferation of satellite cells and differentiation of muscle fibers during regeneration are inducted through extracellular factors released within injured tissue. Among them are growth factors, interleukins, and proteoglycans localized within the extracellular matrix. They affect membrane receptors, and may serve as regulators of the regeneration process. Importantly, satellite cells dissociated from adult muscle and grown in culture are also able to proliferate, fuse and form multinucleate myotubes that synthesize muscle-specific proteins and contract spontaneously (Le Moigne et al., 1990). This characteristic of satellite cells allowed us to exploit in vitro model of myoblast fusion and differentiation. Except differentiation of satellite cells in primary cultures we also investigated fetal myoblast and $\mathrm{C} 2 \mathrm{C} 12$ line of mouse myoblasts. These in vitro studies greatly supplemented analyses performed on regenerating muscles in vivo. Thus, we focused our studies on the mechanism of satellite cell fusion during their differentiation in vitro.

As we mentioned previously, we also conducted analyses of injured muscle regeneration i.e. the process which also engages satellite cells differentiation. Muscle injury similarly as wound healing involves rapid synthesis and degradation of proteins, and also the composition of the extracellular matrix changes over time. We studied important differences in the processes of regeneration between different groups of muscles. In the rat, regeneration following mechanical injury of the extensor digitorum longus (EDL) muscle (composed mostly of rapid-twitch fibers) and the soleus muscle (composed mostly of slow-twitch fibers) exhibits a number of differences (Moraczewski et al., 2002, Moraczewski et al., 1996b). After two weeks following injury EDL muscles regenerate and exhibit an almost normal structure, whereas the soleus undergoes degeneration, and fibrosis (Bassaglia and Gautron, 1995). The extent of degeneration of the extracellular matrix may be a limiting factor in regeneration. In our studies, we elucidated crucial differences in the regeneration of fast- and slow-contracting muscle, as well as the participation of calpains in various stages of myolysis and reconstruction (Moraczewski et al., 1996a, Moraczewski et al., 1996b, Zimowska et al., 2001).

\section{Protein Kinase $\boldsymbol{C}$ activity}

During the differentiation of satellite cells, specific signals control cell proliferation, adhesion, spreading, migration, and fusion. Our first studies on skeletal muscle regeneration focused on enzymes involved in regulation of pathways of signal transduction. Many studies focused on the involvement of protein kinase $\mathrm{C}$ (PKC) in the regulation of neuronal tissue at the cellular level. However, the participation of this enzyme in the maturation of muscle tissue has never been explored previously. We presented evidence that PKC activity changed during fetal and postnatal rat development (Moraczewski et al., 1990) in three crucial stages: before innervation, when polyinnervation develops and after birth, during formation of monoinnervated fibers. PKC activity was low in non-innervated fetal fibers, and reached its maximum prior to birth, at the end of myogenesis, i.e. during the polyinnervation phase. After birth, PKC activity, was principally found in membrane fractions, stabilized as the remodelling of innervation and physiological muscle fibers differentiation proceeded. This postnatal period coincides with synapse elimination during the regression of polyinnervation. Immunocytochemical localization of PKC in fetal and postnatal muscles showed that the enzyme activity detected biochemically was, at least in part, of muscular origin.

The relationship between the activity of protein kinase $C$ and muscle innervation was explored in the rat sternomastoid muscle (SM) from day 18 of gestation (E 18) to adult age (Moraczewski et al., 1991). Sternomastoid muscle was selected due to the fact that all its neuromuscular end-plates are located in the median part, which can easily be dissected and separated from the aneural sections. Between E 18 and birth, PKC activity rose 5fold, and within one day after birth, diminished to a level characteristic for mature muscle. This increase occurred mostly in the neural part of the muscle, in both the membrane and the cytosolic fractions. Denervation of adult SM reduced PKC activity by half in the membrane fraction of the neural part but did not significantly change it in the membrane or cytosol fractions of the aneural parts. These results suggested that innervation plays crucial role in determining the level of PKC activity in muscle. We also analyzed myogenesis within the limb, and showed that PKC activity increased during two crucial stages of limb muscle development i.e. the polyinnervation phase $(E$ I8) and at day 5 after birth, when regression of polyinnervation takes place. We concluded that the level of PKC activity both in SM and in limb muscle was determined by changes in muscle innervation. This assumption was supported by the results obtained in the experiments in what SM was denervated. The drastic decrease in the PKC activity of the membrane fraction of the neural part of the denervated SM muscle showed that most of kinase activity was due to the presence of the nerve ending. 
As we mentioned previously it has been known that fast and slow twitch muscles regenerate differently. However, the differences between both muscle types at the level of expression of a number of enzymes and structural proteins during muscle differentiation in vitro in primary cultures of satellite cells from such muscles were never precisely determined. We were using a model of crush-induced regeneration of denervated muscle in rats (Bassaglia and Gautron, 1995) to study the slow-twitch soleus muscle and the fast-twitch extensor digitorum longus muscle degeneration and regeneration in vivo. In the soleus muscle, myolysis was fast, pronounced and lead to the poor reconstruction of muscle tissue. The activation of satellite cells which occurs by day 3 generated small and irregular myotubes. Two weeks after injury the myotubes were heterogeneous in size and disjointed. Re-innervation of these myotubes did not occur properly and the muscle underwent fibrosis (Bassaglia and Gautron, 1995). In contrast, in the fast-twitch EDL muscle, the degree of myolysis was low and the muscle underwent satisfactory reconstruction. Satellite cells activation and differentiation resulted in regenerated myotubes, which yielded functional myofibres within 2-3 weeks.

It has been shown previously that PKC is implicated also in in vitro growing and differentiating myoblasts and satellite cells (Lagord et al., 1993, Martelly et al., 1989). Moreover, it has been shown that PKC activity varies during rat skeletal muscle development and that denervation affects this activity and $\mathrm{PKC}$ isoform expression (Moraczewski et al., 1991, Moraczewski et al., 1990). Several isoforms of PKC also play a role in muscle metabolism and synapse functions. This data urged us to characterize the possible involvement of PKC in the process of regeneration (Moraczewski et al., 2002). In that study, we used the in vivo model of crush-induced muscle regeneration in soleus and EDL muscles to investigate whether specific changes in PKC activity could be associated with various post-operative phases of crushinduced regeneration. By comparison with contralateral muscles, we have demonstrated changes in PKC activity during the first 14 days following muscle crushing. We have also shown, that the PKC isoforms, which belong to three enzyme subfamilies were sequentially expressed, and in the case of some of them were differentially expressed in soleus and EDL muscles during the process of regeneration. The different levels of PKC activity and different expression of isoforms could be correlated in time with the phases of regeneration. Indeed, an increase in PKC activity was observed in both types of contralateral muscles shortly after operation. This increase was extended at least 1 or 3 days after crushing in EDL and soleus muscles, respectively. Interestingly, in a previous study, we have also shown changes in the activity of calpain in contra-lateral muscles during muscle regeneration using the same crushed muscle model (Moraczewski et al., 1996b). In regenerating muscles, the levels of PKC overall activity were down regulated in the crushed muscles during the first 3 days of regeneration. This loss of activity was correlated in time with the myolysis stage of muscle fibers and the disappearance of the motor end-plates. The increase in PKC activity, which followed, was observed in both EDL and soleus muscles but occurred earlier in EDL than in soleus. This increase in activity did not correlate with the phase of intense satellite cell proliferation that occurred just after myolysis (days 3-4) and which was more intense in the soleus than in EDL as determined by the number of desmin-positive cells. Our results showed that the increase in PKC activity could be correlated with the increase in size of myotubes and their maturation, which occurred after day 3 . Indeed, EDL, which already presented well-structured myotubes on day 7, displayed an early rise in PKC activity compared to the soleus. Our results also clearly showed that different PKC isoforms were expressed sequentially in the course of muscle regeneration. PKC $\zeta, \beta, \eta$ appeared after $\alpha, \varepsilon$, and $\theta$. Some PKC isoforms, $\beta$, were expressed differentially in the two muscle types. For instance, PKC $\delta$ appeared more in intact or regenerating soleus muscle, than in EDL. In contrast, isoforms $\beta$ or $\eta$ were expressed more in EDL than in soleus during regeneration. Taken together, our results, which showed a differential pattern of expression of $\mathrm{PKC}$ isoforms and localization in regenerating muscular tissue, suggested that they might fulfil different functions in this process. The comparative study of the regeneration of slow (soleus) and fast (EDL) twitch muscles, which display some differences in the regeneration process, underline the differential modulation of PKC isoforms in regenerating skeletal muscles.

\section{Calpain activity}

Next enzymes that we focused on were calpains. These nonlysosomal, intracellular, calcium activated neutral proteinases (CANPs) were first characterized in pig muscle. Two isoforms of calpains require either micromolar $\mathrm{Ca}^{2+}$ : micro-calpain, or milimolar $\mathrm{Ca}^{2+}$ : milli-calpain. These enzymes could be involved in both intracellular proteolysis and cytoskeleton reorganization required for myogenic cell fusion. According to (Brustis etal., 1994) calpain $\mathrm{I}$, could be also exteriorised and could play a role in the proteolysis of fibronectin. However during the reconstruction of the extracellular matrix, other metalloproteases play a more important enzymatic role. The mechanism of their activity has not been researched thoroughly during the regeneration of skeletal muscle. Thus, we focused on calpains and showed significant differences in calpain distribution during differentiation of human myogenic cells in vitro (Moraczewski et al., 1996a). We detected $\mu$-calpain within the nuclei of myoblasts and within the cytoplasm of myotubes, whereas m-calpain was only found in the cytoplasm, and was concentrated near the nuclear envelope. Biochemical assays showed that the amounts of these proteinases were modulated during cell growth and differentiation. m-calpain activity was high at the proliferation phase (day 4 of culture) and reached a maximum at the beginning of fusion (day 8) and decreased slightly when the number of myotubes augmented (day 12). This activity profile suggested that $\mathrm{m}$-calpain could play a role in the initiation of fusion of satellite cells. The activity of $\mu$-calpain increased regularly during cell growth and the maximum activity was assayed when the cells differentiated, i.e. when its intracellular localization shifted from the nucleus to the cytoplasm. We concluded that the activity and the intracellular localization of the 2 forms of calpains differ at different stages of differentiation of myogenic cells (Fig. 2).

Moreover, calpains play an important role in the process of myofibrillar protein turnover. They participate in post mortem meat tenderisation. Also, the level of $\mathrm{Ca}^{2+}$ activated proteinases dramatically increased at the early stage of myogenesis. Calpains are one of the major activators of PKC and, according to (Savart et al., 1995), a stable and functional PKC- $\mu$-calpain complex exists in skeletal muscles. In an attempt to clarify the roles of 

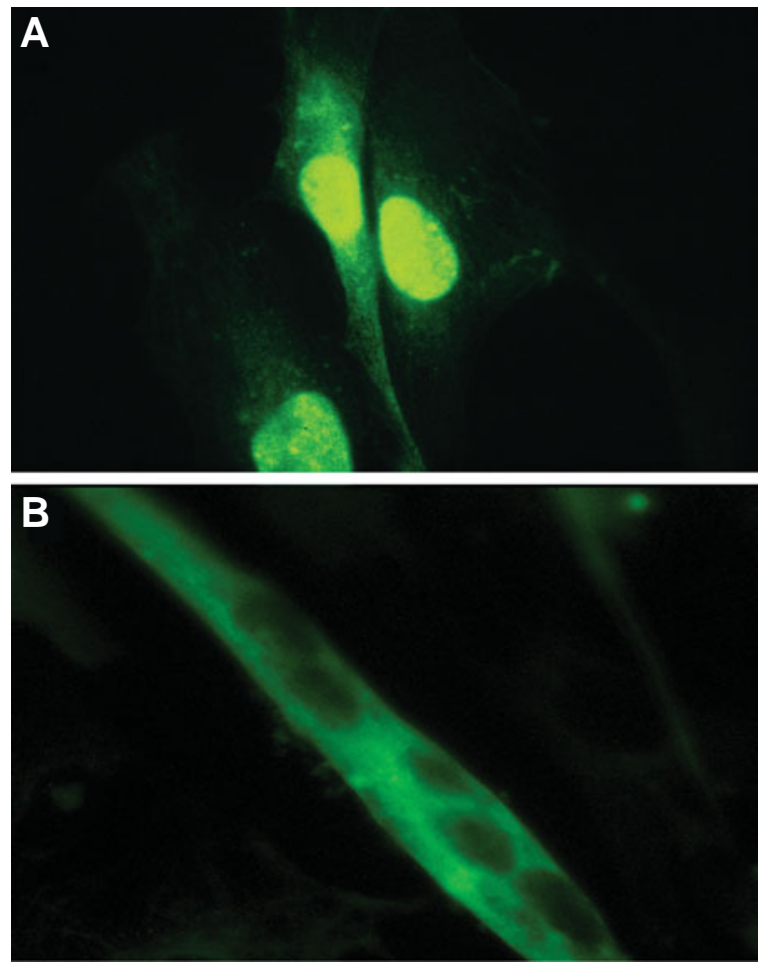

Fig. 2. Localization of calpains during myoblast differentiation. (A) $\mu$ calpain in the nucleus of an undifferentiated myoblast. (B) $\mathrm{m}$-calpain in the cytoplasm of a myotube.

several calpains in muscle regeneration, we investigated changes in calpain levels in fast and slow twitch regenerating and contralateral rat muscles (Moraczewski et al., 1996b). Interestingly, we discovered high level of $\mathrm{m}$-calpain in the soleus muscle from noninjured muscles of non-operated rats. It has been shown previously, that in pig muscles m-calpain was more abundantly expressed within the slow muscle as compared to the fast muscle. Our result shown that $\mathrm{m}$-calpain activity changes induced by the injury was distinctly different in the two analyzed muscles. During EDL regeneration, the level of $\mathrm{m}$-calpain increased. $\mathrm{m}$-calpain was most abundant during formation of muscle fibers. In the soleus muscle, the minimum m-calpain level was observed at the time when myoblast fusion occurred. However, the effect of injury on the contralateral muscle was different. In EDL the activity of both $\mu$-and $m$-calpain in contralateral muscle was of the same as in the non-crushed muscle, while the activity in Soleus muscle generally followed the same trend as in crushed muscle. Our results suggest that, unlike $\mathrm{m}$-calpain, $\mu$-calpain did not play a significant, direct role at the early stage of muscle regeneration.

Ours collaborators from Universite Paris Val de Marne (France) synthesized a new class of compounds - heparane sulfate mimetics (RGTA) that are able to induce the repair of several tissues (Aamiri et al., 1995a, Aamiri et al., 1995b, Desgranges et al., 1999, Gautron et al., 1995). Since, stabilized reinnervation and reduced fibrosis was observed in regenerating soleus muscle treated with RGTA, thus we decided to investigate the changes in expression of $\mu$ - and $\mathrm{m}$-calpain during Soleus muscle regeneration and to explore whether RGTA treatment would influence calpain activity in these muscles (Zimowska et al., 2001). Micro- and milli-calpain levels increased during the fiber reconstruction and reinnervation. Even after 64 days of regeneration, muscles displayed levels of both calpains higher than an intact uninjured muscle. Interestingly, the treatment of muscles with RGTA treatment highly reduced the increase of both milli- and micro-calpain contents levels in regenerating Soleus regenerating muscles. These results suggested that the improvement of muscle regeneration induced by RGTA may have been at least partly mediated by minimizing the consequences of decreasing calpain activity. The ability of RGTA to facilitate regeneration in Soleus muscle showed that this drug could be thus considered as a potential new therapeutic opportunity for the treatment of certain neuromuscular disorders.

Many studies have demonstrated that the fusion of myoblasts into multinucleated myotubes depends on $\mathrm{Ca}^{2+}$. Promoting effect of $\mathrm{Ca}^{2+}$ on myoblast fusion is connected to calcium-dependent activation of calpains (Fig. 2). The role of RGTA in this process is connected to its modulatory influence on both the level and activity of m-calpain. To gain the insight into the mechanism of RGTA action, we explored its effect of a new GAG mimetic (RGD120) on myoblast fusion (Zimowska et al., 2005). To this point we treated the myoblasts isolated from adult rat skeletal muscles and grown in primary cultures with RGD120, and discovered that in vitrocultured myoblasts accelerated their growth rate and underwent precocious fusion into myotubes. RGD120 treatment also partially overcame the inhibitory effect of the calpain inhibitor N-acetyl-leu-leu-norleucinal (ALLN) on these events. In addition, RGD120 added to prefusing myoblast cultures accelerated their fusion into myotubes, and importantly induced an increase of the cytosolic free $\mathrm{Ca}^{2+}$ concentration. In consequence, m-calpain levels and activity was increased by chronic RGD120 treatment. Again, we concluded that effect of RGD120 on the stimulation of myogenesis might have been at least in part explained by its effect on $\mathrm{Ca}^{2+}$ mobilization as well as on the calpain amount and activity.

\section{The role of TGF $\beta 1$}

Growth factors and cytokines that are released from a number of inflammatory cells as well as from damaged muscle fibers, including hepatocyte growth factor (HGF), insuline like growth factors (IGF) and fibroblast growth factors (FGF), are known to modulate the regeneration process. Among them, growth factors belonging to the TGF $\beta$ family seem to play a specific role during muscle repair. Members of TGF $\beta$ family play an important role in fibrosis development and scar formation since they stimulate extracellular matrix (ECM) production, modulate the expression of ECM-degrading enzymes, increases the expression of proteinase inhibitors. Among this family of growth factors TGF $\beta 1$ gained our particular attention.

The main hypothesis explored in our study was that the different regeneration ability of EDL and Soleus muscles could be associated with differential expression of TGF $\beta 1$ during the repair process. Primary cultures of myoblasts extracted from Soleus and EDL muscles separately made possible the analysis of contribution of myoblasts in TGF- $\beta 1$ expression level and determine whether differences during repair process could results from intrinsic property of myoblast cells.

The muscle environment has a profound effect on the regenerative capacity of resident muscle precursor cells and implanted 
cells. Among ECM components, glycoaminoglycans (GAG) have been implicated in numerous processes such as enzyme regulation, cellular adhesion, growth, migration and differentiation. Since it is known that sulphated GAGs regulate TGF $\beta$ activity, special attention was paid to the possibility that these molecules produced by fast and slow muscles or by their derivating myoblasts could account for the differences of quality of regeneration.

We found that the extensive fibrosis evident in the soleus muscle was accompanied by elevated TGF $\beta 1$ level. Thus, decreasing of TGF $\beta 1$ level appeared promising of muscle repair improvement. Indeed, the consequences of TGF $\beta 1$ attenuation using antibodies has been examined in regenerating muscles in vivo as well as in myoblasts in primary cultures in vitro. We found that impairment of TGF $\beta 1$ action resulted in an acceleration and improvement of the soleus muscle repair process in vivo as well as increased Soleus derived myoblast growth and their precocious fusion into myotubes in vitro. Importantly, the reduction of TGF $\beta 1$ was also accompanied by and alteration of GAG levels. These findings indicated that the precise control of TGF $\beta 1$ activity was needed to improve the regeneration of injured muscle and myoblast differentiation and that this effect might have been in part mediated through GAG composition of the muscle cell environment.

\section{Myoblast fusion}

Changes in the structure of cell contact and cellular adhesion during the differentiation of satellite cells derived myoblasts in vitro was yet another important aspect of the studies on muscle regeneration carried out in our laboratory. We were especially interested to expose the role of syndecans, talin, cadherin, and integrins in this process.

Syndecan-4 and talin play a crucial role in maintaining proper function of focal contacts (FC) i.e. areas where cells contact with the extracellular matrix (ECM). Analyses of FC functions seemed crucial to us since they play essential role in: adhesion to the ECM, migration and signal transduction leading to cell proliferation, growth, differentiation, apoptosis, and gene expression i.e. processes that are vital for myoblasts differentiation. Moreover, syndecans (transmembrane heparan sulfate proteoglycans) was shown to have a potential role in muscle development. Syndecan3 and syndecan-1 are expressed in $\mathrm{C} 2 \mathrm{C} 12$ mouse myoblasts. Syndecan-3 and syndecan-4 are also expressed on quiescent satellite cells, and are necessary to their activation. Moreover, syndecan-4 can influence cell adhesion. Interactions of syndecan-
4 with PKC isoforms were the main mechanism that regulates its distribution in cells. Thus, we investigated the role of syndecan4 during the differentiation of activated satellite cells (Brzoska et al., 2003). This study showed that syndecan-4 was localized at the cell membrane of differentiating cells and after PKC activation by phorbol esters (TPA) it formed long focuses along the myoblast. Though, inhibition of PKC by Calphostin $\mathrm{C}$ (Cal C) resulted also in forming clusters along myoblasts. However, there were no differences in syndecan-4 localization in control and treated cultures in myotubes. We speculated that the causes of changes in syndecan-4 distribution after TPA or Cal $C$ treatment were interactions with activated PKC $\alpha$ and inhibited PKC $\delta$. Interestingly, changes in syndecan-4 distribution that were observed in cells treated either with TPA or with $\mathrm{Cal} C$ had no influence on myoblast differentiation. We suggested that TPA treatment led to PKC $\alpha$ activation, which provoked syndecan-4/PKC $\alpha$ complex translocation to integrins. On the overhand $\mathrm{Cal} C$ treatment inhibited $\mathrm{PKC} \delta$ activity and probably induced $\mathrm{PKC} \alpha$ association to syndecan-4, and syndecan-4 translocation to integrins.

We also followed the changes of talin localization and phosphorylation during the differentiation of myoblasts to myotubes (Brzoska et al., 2004). This adhesion protein, present in variety of tissues and cell types, binds actin filaments to integrins and the plasma membrane. Its function depends on phosphorylation status. Our studies revealed that the level of talin expression during differentiation was constant in both the control and TPA treated cells. We noticed the presence of talin in FC and cell-cell contact in differentiating myoblasts. Moreover, we demonstrated FC and cell-cell contacts contained only unphosphorylated form of talin. In the cells treated for $24 \mathrm{~h}$ or $48 \mathrm{~h}$ with TPA the level of talin phosphorylation increased (as evidenced by talin being present in the cytosol). However talin localization did not change, and moreover, FCs still contained only unphosphorylated form of talin. Increase time of culture resulted in decrease of talin phosphorylation and furthermore in redistribution of talin that started to form long foci near the plasma membrane. The presence of TPA did not influence myoblast differentiation but changed talin localization in differentiated myotubes.

Satellite cells become activated after muscle injury or after their isolation from muscle and in vitroculture. Such cells proliferate, migrate and fuse into multinucleate myotubes to form muscle fibers (Fig. 3A). The myoblast fusion is the most complex stage of cell differentiation. It is preceded by the formation of temporary cell-cell contacts that is followed by the intracellular adhesion.

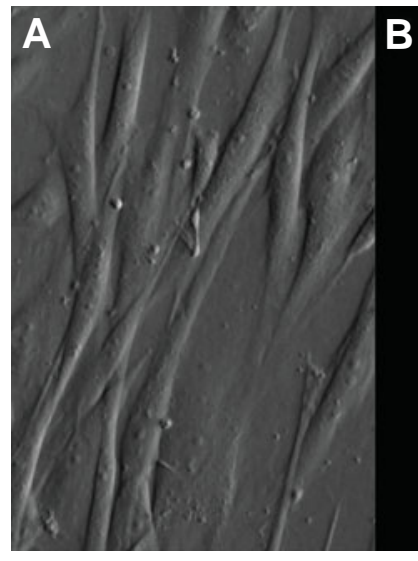

B

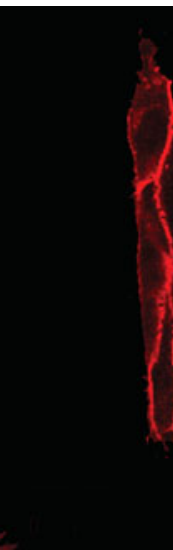

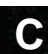
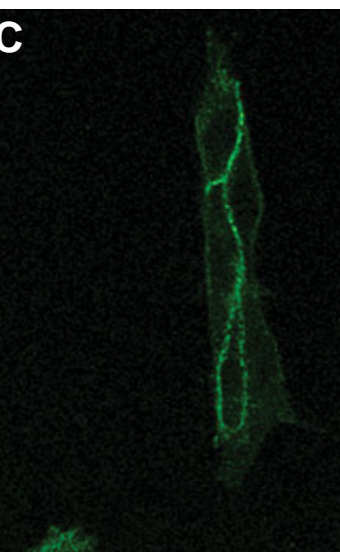

D

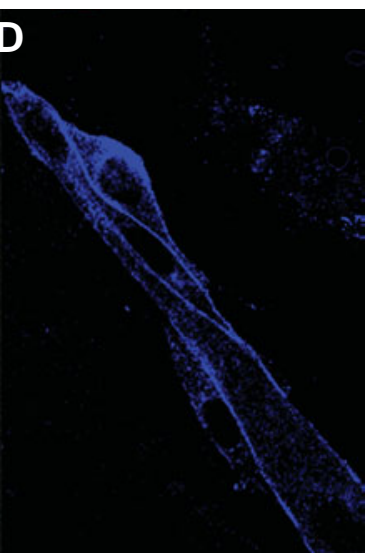

Fig. 3. Localization of the most significant proteins involved in myoblast fusion. (A) Fusing myoblasts in a rat primary cell culture on day 7 in vitro. (B-D) Optical slides (confocal microscopy). (B) Immunocytochemical localization of $M$ cadherin in the cell membrane of fusing myoblasts. (C) $\beta$-catenin in the membrane of fusing cells. (D) Localization of the integrin $\alpha 3$ subunit between fusing myoblasts. 
The specificity of cellular adhesion results from combinatorial expression and interactions of transmembrane molecules at the cell-cell and cell-matrix contacts. The function of cell adhesion proteins affects many aspects of cell behaviour such as cell shape and polarization, cytoskeletal organization, cell motility, proliferation, survival, cell differentiation and the structure, integrity and function of cells and tissues. Cell adhesion molecules (CAMs) that belong to four major categories: cadherins, integrins, selectins and the immunoglobulin super family are widely involved in morphogenesis, embryogenesis and organogenesis by mediating adhesive processes within differentiating tissues. It has been demonstrated that during differentiation myoblasts recognize one another, adhere and align to form linear aggregates, and then cells fuse into myotubes. However, the mechanisms underlying these processes remain obscure. We decided to explore these problems by studying the role of cadherins, integrins and ADAM12 protein.

During myogenesis, cadherins are involved in the initial cell-tocell recognition and it has also been suggested that they play a role in the initiation of myoblast fusion. Cadherins belong to a large family of membrane glycoprotein adhesion receptors that mediate haemophilic, calcium-dependent cell adhesion. One of the members of the cadherin family, M-cadherin, has been found during embryogenesis in myogenic cells of somitic origin and in adult muscles. We investigated the distribution and function of $\mathrm{M}$ cadherin and $\beta$-catenin during differentiation of myoblasts in primary cultures of rat satellite cells (Wrobel etal., 2007). First, we noticed that $\mathrm{M}$-cadherin with $\beta$-catenin localized between fusing myoblasts and that $\beta$-catenin colocalized with actin in pre-fusing myoblasts (Fig. $3 \mathrm{~B}, \mathrm{C}$ ). We showed that increases of the mRNA level and $\mathrm{M}$-cadherin and $\beta$-catenin protein synthesis accompanied myoblast differentiation. We performed experiments using an antibody specific for the extracellular domains of M-cadherin and showed that it inhibited the fusion of cultured myoblasts. Our observations suggest significant role of M-cadherin in the differentiation of satellite cells and in myoblast fusion in primary cultures

Moreover, we showed (Brzoska et al., 2006a), that the integrin $\alpha 3$ subunit was expressed in quiescent and activated satellite cells and was localized at cell-cell and cell-extracellular matrix contacts during myoblasts differentiation (Fig. 3D). During myoblasts differentiation the level of protein and mRNA encoding the integrin $\alpha 3$ subunit increased. Importantly, we demonstrated that the integrin $\alpha 3$ subunit colocalizes with actin, and binds to the integrin $\beta 1$ subunit and ADAM 12 in fusing myoblasts. We strongly suggested that the $\alpha 3 \beta 1 /$ ADAM 12 complex played important role in the myoblast fusion. Moreover, we investigated involvement of integrin $\alpha 3$ subunit and showed that overexpression of the fulllength integrin $\alpha 3$ subunit increased, whereas an antibody against its extracellular domain inhibited myoblast fusion. Ours results showed that integrin a3 subunit contributed to satellite cell activation and then myoblast adhesion and fusion.

\section{Stem cells in muscle regeneration}

We are also conducting research on the role of stem cells from other tissues in the regeneration of skeletal muscle. This research is being performed in cooperation with the Department of Clinical Cytology, Medical Center of Postgraduate Education, Warsaw, and Department of Experimental Haematology, Maria Sklodowska-
Curie Memorial Cancer Center and Institute of Oncology, Warsaw.

Stem cells from different tissues may be involved in the regeneration of damaged muscle. Furthermore, stem cells isolated from adult bone marrow, the neuronal compartment, and mesenchymal tissues are able to follow myogenesis in vitro or in vivo. In our studies we paid special attention to umbilical cord blood (HUCB). HUCB is characterized by containing stem cells. We transplanted HUCB cells into injured muscles of SCID (severe combined immunodeficient) mice and showed that they could contribute to muscle regeneration and remained present within the muscle at least for one month (Brzoska et al., 2006b). Importantly, they were able to fuse with the mouse myoblasts. Moreover, the implanted HUCB cells formed human muscle precursor cells residing within the mouse repaired muscle. Since, we observed changes in the number of HUCB cells in muscle and showed that they expressed CXCR4 receptor we investigated the level of SDF-1 (stromal derived factor-1) in regenerating muscle. We demonstrated that SDF-1 is secreted in regenerating muscle, what strongly suggested that HUCB cells translocation after transplantation depended on changes in SDF-1 expression.

Yet another stem cell type that we analyzed in our experimental model of muscle injury was fetal rat liver cells (Machaj et al., 2005). The fetal liver is the source of early hematopoietic cells and also, as a fetal tissue, may be considered as a source of pluripotent stem cells. Results of our experiments suggested that in the liver of rat embryo at 14 day of embryonic development at least two subpopulations of cells could be distinguished. One - the nonadherent hematopoietic cell population that was not capable of myogenesis. The second population of plastic-adherent cells were able to fusion with myoblasts and differentiation into myotubes. Currently accessible data suggests that mid-gestation fetal liver contains stem cells, but not toti- or multipotent ones. We hope that transplantation of non-embryonic stem cells could present a possibility for muscle therapy.

\section{Concluding remarks}

This overview summarizes our previous studies which have concentrated on the elucidation of the processes linked to cell differentiation during muscle regeneration. We consider that cell fusion is one of the most important events during both muscle differentiation during normal development and in regeneration. Thus, our future projects focus on the mechanisms of the initiation, regulation and progress of myoblast fusion. Moreover, we plan to pursue the important issue of muscle regeneration at the molecular and cellular level. We hope that at least some of our findings could amplify current knowledge of the basis of certain myopathies.

\section{Acknowledgements}

We would like to thank all our laboratory colleagues, especially Isabelle Martelly and Edyta Wrobel, for their participation in the studies on regeneration.

\section{References}

AAMIRI, A., BUTLER-BROWNE, G.S., MARTELLY, I., BARRITAULT, D. and GAUTRON, J. (1995a). Influence of a dextran derivative on myosin heavy chain expression during rat skeletal muscle regeneration. Neurosci Lett201: 243-6. 
AAMIRI, A., MOBAREK, A., CARPENTIER, G., BARRITAULT, D. and GAUTRON, J. (1995b). [Effects of substituted dextran on reinnervation of a skeletal muscle in adult rats during regeneration]. C R Acad Sci II/318: 1037-43.

BASSAGLIA, Y. and GAUTRON, J. (1995). Fast and slow rat muscles degenerate and regenerate differently after whole crush injury. J Muscle Res. Cell Motility 16: 420-429.

BRUSTIS, J.J., ELAMRANI, N., BALCERZAK, D., SAWATE, A., SORIANO, M., POUSSARD, S., COTTIN, P. and DUCASTAING, A. (1994). Rat myoblast fusion requires exteriorized m-calpain activity. Eur. J. Cell. Biol. 64: 320-327.

BRZOSKA, E., BELLO, V., DARRIBERE, T. and MORACZEWSKI, J. (2006a). Integrin alpha3 subunit participates in myoblast adhesion and fusion in vitro. Differentiation 74: 105-18.

BRZOSKA, E., GRABOWSKA, I., HOSER, G., STREMINSKA, W., WASILEWSKA, D., MACHAJ, E.K., POJDA, Z., MORACZEWSKI, J. and KAWIAK, J. (2006b). Participation of stem cells from human cord blood in skeletal muscle regeneration of SCID mice. Exp Hemato/34: 1262-70.

BRZOSKA, E., GRABOWSKA, I., WROBEL, E. and MORACZEWSKI, J. (2003). Syndecan-4 distribution during the differentiation of satellite cells isolated from soleus muscle treated by phorbol ester and calphostin C. Cell Mol Biol Lett 8 : 269-78.

BRZOSKA, E., WROBEL, E., GRABOWSKA, I. and MORACZEWSKI, J. (2004). Talin distribution during the differentiation of satellite cells isolated from rat skeletal muscle. Cell Mol Biol Lett 9: 723-37.

DESGRANGES, P., BARBAUD, C., CARUELLE, J.P., BARRITAULT, D. and GAUTRON, J. (1999). A substituted dextran enhances muscle fiber survival and regeneration in ischemic and denervated rat EDL muscle. Faseb J13: 761-6.

DUMA, A. and MORACZEWSKI, J. (1980). Ultracytochemistry of cyclic 3',5'nucleotide phosphodiesterase activity in the planarian Dugesia lugubris $(\mathrm{O}$. Schmidt). Histochemistry 66: 211-20.

FRANQUINET, R. (1979). [The role of serotonin and catecholamines in the regeneration of the Planaria Polycelis tenvis]. JEmbryolExp Morpho/51: 85-95.

FRANQUINET, R. and CATANIA, R. (1979). Localisation et etude microspectrofluorimetrique de la serotonine et des catecholamines chez la Planaire normalne et en regeneration. C.R. Acad. Paris.

FRANQUINET, R. and LE MOIGNE, A. (1979). Relations entre les variations des taux de serotine et d'AMP cyclique au cours de la regeneration d'une Planaire. Biol. Cell. 34: 71-76.

FRANQUINET, R., LE MOIGNE, A. and HANOUNE, J. (1978). The adenylate cyclase system of planaria Polycelis tenuis: activation by serotonin and guanine nucleotides. Biochim Biophys Acta 539: 88-97.

FRANQUINET, R. and MARTELLY, I. (1981). Effects of serotonin and catecholamines on RNA synthesis in planarians; in vitro and in vivo studies. Cel/ Differ 10: 201-9.

FRANQUINET, R., STENGEL, D. and HANQUNE, J. (1976). The adenylate cyclase system in a freshwater planarian (Polycelis tenius lijima). Comp Biochem Physiol B53: 329-33.

GAUTRON, J., KEDZIA, C., HUSMANN, I. and BARRITAULT, D. (1995). Acceleration of the regeneration of skeletal muscles in adult rats by dextran derivatives. C R Acad Sci II/318: 671-6.

LAGORD, C., CARPENTIER, G., LEIBOVITCH, M.P., GAUTRON, J. and MARTELLY, I. (1993). Stimulation of rat satellite cell myogenesis by inhibitors of ser/thr protein kinases. Neuromuscul Disord 3: 379-83.

LE MOIGNE, A., MARTELLY, I., BARLOVATZ-MEIMON, G., FRANQUINET, R., AAMIRI, A., FRISDAL, E., BASSAGLIA, Y., MORACZEWSKI, G. and GAUTRON, J. (1990). Characterization of myogenesis from adult satellite cells cultured in vitro. Int J Dev Bio/34: 171-80.

LE MOIGNE, A., MARTELLY, I. and FRANQUINET, R. (1976). Variation des syntheses d'ARN et de nucleotides cyclique au cours de la regeneration des Planaries. Bull. Soc. Zool. France 101: 29-33.

LENDER, T. and KLEIN, N. (1961). Mise en evidence de cellules secretrices dans le Planaire Polycelis nigra. Variation de leur nombre au cours de la regeneration posterieure. C.R. Acad. Sci. 253: 331-333.

LENICQUE, P.M. (1973). Morphogenetic action of 5 hydroxytryptamine and some analogues substances on the regeneration of the planarian worm Dugestia tigrina. Acta Zool. 54: 131-137.
MACHAJ, E.K., GRABOWSKA, I., GAJKOWSKA, A., JASTRZEWSKA, M., OLDAK, T., MORACZEWSKI, J. and POJDA, Z. (2005). Differentiation potential of the fetal rat liver-derived cells. Folia Histochem Cytobio/43: 217-22.

MARTELLY, I., GAUTRON, J. and MORACZEWSKI, J. (1989). Protein kinase C activity and phorbol ester binding to rat myogenic cells during growth and differentiation. Exp Cell Res 183: 92-100.

MORACZEWSKI, J. (1977). Asexual reproduction and regeneration of Catenula (Turbellaria, Archoophora). Zoomorphologie 88: 65-80.

MORACZEWSKI, J. (1981). Cell activation during regeneration of Planarians. Hydrobiologia 84: 203-207.

MORACZEWSKI, J. and CZUBAJ, A. (1974). Muscle ultrastructure in Catenula lemnae /Dug/Turbellaria, Archoophora/. J. Submicr. Cytol.29-38.

MORACZEWSKI, J., CZUBAJ, A. and BAKOWSKA, J. (1977a). Organization and ultrastructure of the nervous system in Catenulida (Turbellaria). Zoomorphologie 87: 87-95.

MORACZEWSKI, J., CZUBAJ, A. and KWIATKOWSKA, J. (1977b). Localization of neurosecretion in nervous system in Catenulida (Turbellaria). Zoomorphologie 87: 97-102.

MORACZEWSKI, J. and DUMA, A. (1978). Ultrastructural localization of adenyl cyclase activity in neoblasts of turbellarian Dugesia lugubris O. Schmidt. J Exp Zool203: 491-496.

MORACZEWSKI, J. and DUMA, A. (1981). Localization of adenylate cyclase activity in the tissues of an intact planarian Dugesia lugubris (O. Schmidt). Histochemistry 71: 301-11.

MORACZEWSKI, J. and FRANQUINET, R. (1980). Mise en evidence et activite des proteines kinasses AMP cyclique dependantes et AMP cyclique independantes chez la Planaria Polycelis tenuis. C.R. Acad. Paris 290: 1567-1570.

MORACZEWSKI, J., FRANQUINET, R. and LE MOIGNE, A. (1983). Characterization and activity during planarian regeneration of two types of protein kinases: cyclic AMP-dependent and calcium dependent-cyclic AMP independent. Biol. Cell. 47: 171-178.

MORACZEWSKI, J., GAUTRON, J., DUMA, A., LE MOIGNE, A. and MARTELLY, I. (1991). Changes in protein kinase $C$ activity or rat sternomastoid muscle during development and after denervation. Experientia 47: 241-245.

MORACZEWSKI, J., MARTELLY, I. and FRANQUINET, R. (1986). Protein phosphorylation and the role of $\mathrm{Ca}^{2+}$ in planarian turbellarian regeneration. Hydrobiologia 132: 223-227.

MORACZEWSKI, J., MARTELLY, I., FRANQUINET, R. and CASTAGNA, M. (1987). Protein kinase $\mathrm{C}$ activity during planarian regeneration. Comp. Bioch. Physiol. 87B: 703-707.

MORACZEWSKI, J., MARTELLY, I., TRAWICKI, W., PILARSKA, M., LE MOIGNE, A. and GAUTRON, J. (1990). Activity of protein kinase $C$ during development in rat skeletal muscle. Neuroscience research communications 7: 183-189.

MORACZEWSKI, J., NOWOTNIAK, A., WROBEL, E., CASTAGNA, M., GAUTRON, J. and MARTELLY, I. (2002). Differential changes in protein kinase $C$ associated with regeneration of rat extensor digitorum longus and soleus muscles. Int $J$ Biochem Cell Bio/34: 938-49.

MORACZEWSKI, J., PIEKARSKA, E., BONAVAUD, S., WOSINSKA, K., CHAZAUD, B. and BARLOVATZ-MEIMON, G. (1996a). Differential intracellular distribution and activities of $\mathrm{mu}$ - and $\mathrm{m}$-calpains during the differentiation of human myogenic cells in culture. C R Acad Sci II/319: 681-6.

MORACZEWSKI, J., PIEKARSKA, E., ZIMOWSKA, M. and SOBOLEWSKA, M. (1996b). Activity of mu- and m-calpain in regenerating fast and slow twitch skeletal muscles. Acta Biochim Po/43: 693-700.

SAVART, M., VERRET, C., DUTAUD, D., TOUYAROT, K., ELAMRANI, N. and DUCASTAING, A. (1995). Isolation and identification of a mikro-calpain-protein kinase $C$ alpha complex in skeletal muscle. FEBS Lett. 359: 60-64.

SOLTYNSKA, M.S., MROCZKA, B. and MORACZEWSKI, J. (1976). Ultrastructure of epidermis in Turbellaria from the family Catenulida/Archoophora/. J. Sulmier. Cytol.293-301.

WAGNER, F. (1890). Zur Kenntnis der ungeschlechtlichen Fortpflanzung von Microstoma nebst allgemeinen Bemerkungen uber Teilung und Knospung im Tierreich. Zool. Jahrb. Anat. 4: 349-423.

WOLPERT, L. (1969). Positional information and the spatial pattern of cellular differentiation. J Theor Bio/25: 1-47. 
WOLPERT, L. (1971). Positional information and pattern formation. Curr. Top. Dev. Biol. 6: 183-224.

WROBEL, E., BRZOSKA, E. and MORACZEWSKI, J. (2007). M-cadherin and betacatenin participate in differentiation of rat satellite cells. Eur J Cel/ Bio/86: 99109.

ZIMOWSKA, M., CONSTANTIN, B., PAPY-GARCIA, D., RAYMOND, G., COGNARD, C., CARUELLE, J.P., MORACZEWSKI, J. and MARTELLY, I. (2005). Novel glycosaminoglycan mimetic (RGTA, RGD120) contributes to enhance skeletal muscle satellite cell fusion by increasing intracellular $\mathrm{Ca}^{2+}$ and calpain activity. J Cell Physio/205: 237-45.

ZIMOWSKA, M., SZCZEPANKOWSKA, D., STREMINSKA, W., PAPY, D., TOURNAIRE, M.C., GAUTRON, J., BARRITAULT, D., MORACZEWSKI, J. and MARTELLY, I. (2001). Heparan sulfate mimetics modulate calpain activity during rat Soleus muscle regeneration. J Cell Physio/188: 178-87.

\section{Related, previously published Int. J. Dev. Biol. articles}

See our recent Special Issue Developmental Biology in Poland edited by Kloc, Maleszewski and Tarkowski at: http://www.ijdb.ehu.es/web/contents.php?vol=52\&issue=2-3

See our Special Issue Mammalian Reproduction \& Development in honor of Anne McLaren and edited by Brigid Hogan at: http://www.ijdb.ehu.es/web/contents.php?vol=45\&issue=3

Calpain 2 expression pattern and sub-cellular localization during mouse embryogenesis Fabrice Raynaud, Anne Marcilhac, Karim Chebli, Yves Benyamin and Mireille Rossel Int. J. Dev. Biol. (2008) 52: doi: 10.1387/ijdb.072448fr

\section{Characterization of novel genes expressed specifically in the sexual organs of the planarian Dugesia ryukyuensis}

Sumitaka Hase, Emiko Kashiwagi, Kazuya Kobayashi, Motonori Hoshi and Midori Matsumoto

Int. J. Dev. Biol. (2007) 51: 345-349

Expression of DjXnp, a novel member of the SNF2-like ATP-dependent chromatin remodelling genes, in intact and regenerating planarians.

Leonardo Rossi, Paolo Deri, Ilaria Andreoli, Vittorio Gremigni, Alessandra Salvetti and Renata Batistoni

Int. J. Dev. Biol. (2003) 47: 293-298

The role of p53 in vivo during skeletal muscle post-natal development and regeneration: studies in p53 knockout mice.

Jason D White, Collins Rachel, Royce Vermeulen, Marilyn Davies and Miranda D Grounds

Int. J. Dev. Biol. (2002) 46: 577-582

Planarian pharynx regeneration revealed by the expression of myosin heavy chain-A.

Tomoko Sakai, Kentaro Kato, Kenji Watanabe and Hidefumi Orii

Int. J. Dev. Biol. (2002) 46: 329-332

Limb muscle development.

Bodo Christ and Beate Brand-Saberi

Int. J. Dev. Biol. (2002) 46: 905-914

TNEX59, a planarian regional nuclear factor differentially expressed during regeneration

J Fernandez-Rodriguez, A Cardona, V Hernandez, R Romero, D Bueno

Int. J. Dev. Biol. (2001) 45: S125-S126

Functional analysis of the eye genetic network in planarian regeneration D Pineda, J Gonzalez-Linares, M Marsal, E Salo

Int. J. Dev. Biol. (2001) 45: S123-S124

Disto-proximal regional determination and intercalary regeneration in planarians, revealed by retinoic acid induced disruption of regeneration.

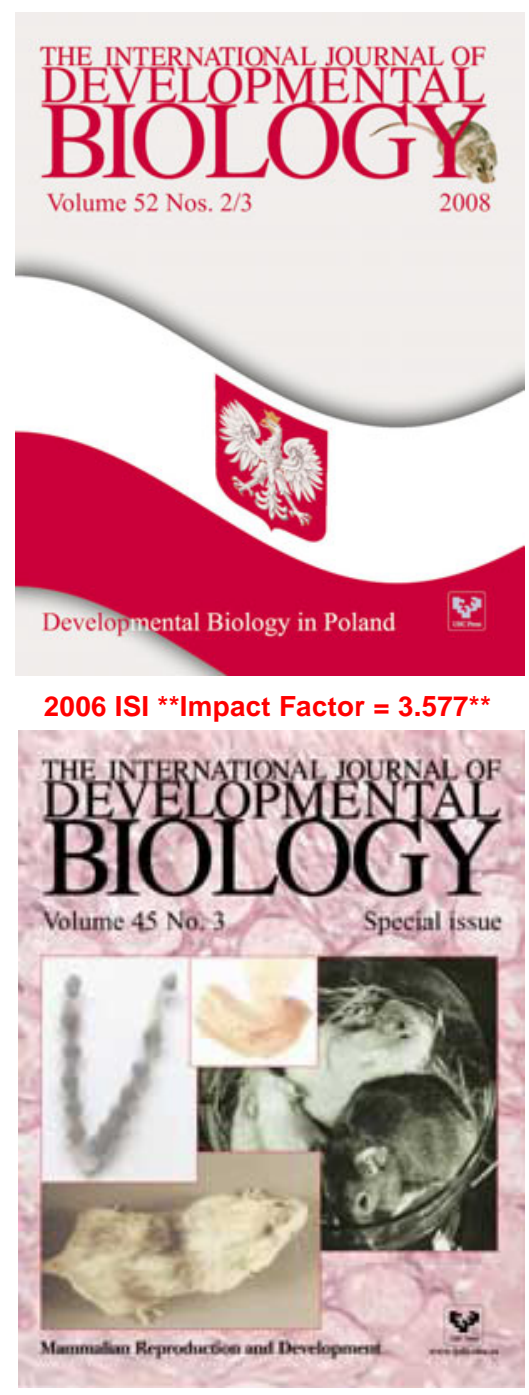

R Romero and D Bueno

Int. J. Dev. Biol. (2001) 45: 669-673 